\title{
Landslides in the Kashmir Earthquake of 8th October 2005
}

\author{
Amita Sinvhal*, Ashok D Pandey and Sachin M Pore \\ Department of Earthquake Engineering, Indian Institute of Technology Roorkee Roorkee-247 667, Uttarakhand, INDIA \\ * For correspondence, email: amitafeq@gmail.com
}

\section{The Event}

A devastating earthquake (MW 7.3) occurred on 8 October 2005 at $03 \mathrm{~h} 50 \mathrm{~m}$ 38.63s UTC, (09:20:38, Indian Standard Time), with epicenter at Muzaffarabad, $34.432^{\circ} \mathrm{N}, 73.537^{\circ} \mathrm{E}$ (NEIC), in Kashmir. The epicenter was located $125 \mathrm{~km}$ WNW of Srinagar, more than $700 \mathrm{~km}$ from Delhi and $90 \mathrm{~km}$ NE of Islamabad. The earthquake devastated the Kashmir valley on both sides of the Line of Control (LoC). Neighboring Afghanistan was also partly affected.

\section{Seismotectonic aspects of the damaged area}

The Himalayan arc is one of the most seismically active regions on the continental crust. Seismicity in this inter-plate environment is attributed to seismotectonic evolution of the Himalayas. These rugged mountain ranges were formed as a result of several tectonic upheavals that were spread through several geologic eras. It started with the movement of the Indian plate through the Tethys Sea, which led to subduction of the oceanic part of the Indian plate below the Eurasian plate, and eventually continent - continent collision between the two plates. Thus, rocks that show evidence of sedimentary, igneous (volcanic) and metamorphic activity in different orogenic episodes are found juxtaposed with each other within the various mountain ranges of the Himalayas. This has caused faulting, thrusting, shearing, folding, fissuring, jointing and alluvial fills in the Himalayan compression zone. This seismotectonic situation, together with action produced by rivers and glaciers over geological time, has rendered mountain ranges in this region vulnerable to steep and precarious slopes, which are sometimes almost vertical, prone to landslides, rock slides, rock falls, mud slides, debris fans, and ground fissures.

The Main Boundary Fault (MBF) and the Main Central Thrust (MCT) defines the southern flank of the entire Himalayan arc. The MBF separates the rugged mountains of the Lesser Himalayas from the sedimentary sequence of the Sub-Himalayas. In the eastern and western extremities of the Himalayas, the Himalayan arc and with it the MBF, take a sharp southward bend. This makes the tectonics in this region more complex than in the rest of the Himalayas. In the area affected by the Saturday morning earthquake the Kashmir syntaxis is the most prominent tectonic feature. The epicentral region, defined by the Balakot - Muzaffarabad region, is on the southern flank of this syntaxis.

Landslides

Shaking produced by the inter-plate earthquake of October 8,2005 in this kind of a geological setting triggered numerous gigantic landslides (Figure 1). These were of unusual dimensions and were spread in a wide geographical region on both sides of the LoC. These included the rugged Pir Panjal and Shamshabari mountain ranges and several river courses, water tributaries and valleys of the Jhelum, Kishan Ganga, Neelam, Qazi Nala and
Kahmil and their many tributaries within Uri and Tangdhar bowls and became more severe beyond that, towards the epicenter. Their incidence and volume of debris increased towards the epicenter, which is in the MBF and MCT region.

The depth of river and valleys ranges from 30 to $70 \mathrm{~m}$ with nearly vertical sidewalls in Jhelum between Baramulla and Uri at several places. Landslides in this stretch were with almost vertical faces as if knife cut, and the starting point was a rotational landslide. Soil profile exposed in landslides, road cuttings and along rivers cuttings revealed an abundance of either highly weathered rocks, including sandstone and conglomerates that were highly heterogeneous in nature. The latter sometimes appeared to be studded with angular or rounded boulders and stones of varying sizes ranging from $50 \mathrm{~mm}$ (size of pebbles) to $500 \mathrm{~mm}$ (boulders) and at many locations huge boulders of size even up to $2.0 \mathrm{~m}$ were encountered. These were embedded in gravel, sand of native rock material, silt, clay and other suspended matters that rivers and streams or glaciers have carried over millennia. The color of exposed soil deposits varied from white-gray to light brown to dusty pink. Isolated patches of very fine and jet-black colored soil deposits were noticed at Kamalkot.

\section{Effects}

The earthquake on 8th October, 2005 triggered massive landslides in the surveyed region and caused havoc in hills surrounding Uri, Baramulla, Salamabad, Kamanpost, Kamalkot, Nasta Chun Pass, Tangdhar and Tithwal. Rolling down of debris and large size stones which occurred near places of habitat or where life line structures were present caused roadblocks and extensive damage due to boulders finding their way into or through structures causing loss of life and property. Several human settlements were buried, rivers were partly obstructed and roads were blocked.

Roads connecting major urban locations are of permanent type with flexible pavements. Few stretches along the valley are without provision of pavement. No structural failure of these roads was observed. Obstruction to traffic was mainly due to deposition of debris on account of landslides from adjacent hills. Landslides blocked national highway NH1A, between Baramula and Uri, but roads were cleared within two days of the earthquake. Ample evidence supporting this fact was present by the roadside. Damage to roads due to numerous landslides was of local extent in spite of large size boulders leaping and rolling down hill slopes and hitting the road surface. This shows a desirable performance of forming the embankments with necessary compaction and stabilization.

Landslides adversely affected several fair weather roads also, including the strategically vital road link to Tangdhar and Tithwal. This zigzag road was stabilized with protection walls, made of random rubble stone masonry. It was covered with debris produced by earthquake induced translational type of landslide, 
and was cleared immediately after the main event, but was prone to after shocks. In these places old and new trees showed a peculiar trend, curving of trunk at its base, symptomatic of continuing creep on steep hills. Various kinds of landslides were observed at different places, e.g. debris flow at Kamalkot, earth flow at Salamabad, crescent shaped crown of landslides at Tangdhar, and topples near Tithwal, etc.

Road embankments at several locations failed partially on slopes. Landslides and embankment slope failures blocked roads at many spots over stretches extending $100 \mathrm{~m}$ at some places. Moderate to severe damage was also observed to slope protection works in the areas surveyed. Failure of stone pitching, breast walls, gabion walls and wing-walls of bridge abutments were observed between Salamabad and Kamalkot as well as on the route to Tangdhar-Tithwal.

On account of the size, and quantity of observed landslides, rockfalls, mudslides, ground fissures etc. in the Pir Panjal and the Shamsabari ranges and in the valleys of Jhelum and Kishanganga and their tributaries, and damage to the built environment in the surveyed region intensities were assigned to various places on the MSK scale, and it varied from MSK XI to MSK VII. At Kamalkot, Salamabad, Uri, Panzgam, Naichian, Tangdhar, Chamkote, Tithwal, Nasta Chun Pass it was XI, at Lagama it was X, at Mohura, Rajarwani, Kupwara, it was IX, at Boniyar, Chandanwari, Rampur, Handwara it was VIII and at Baramula, Srinagar and Pattan it was VII.

\section{Conclusions}

The seismotectonic environment of the region makes it extremely prone to seismic events of varying magnitudes with regular frequency. The extensive landslides, slope failures and rock fall as observed in the surveyed region are an indication of its vulnerability to repeated occurrences of such phenomena and associated damage.

\section{Acknowledgements}

The authors are indebted to the following whose help and support made this field visit possible: The people of Jammu and Kashmir, the Director, IIT Roorkee, the Head, Department of Earthquake Engineering, IIT Roorkee, and Officers and Ranks of the Indian Army.

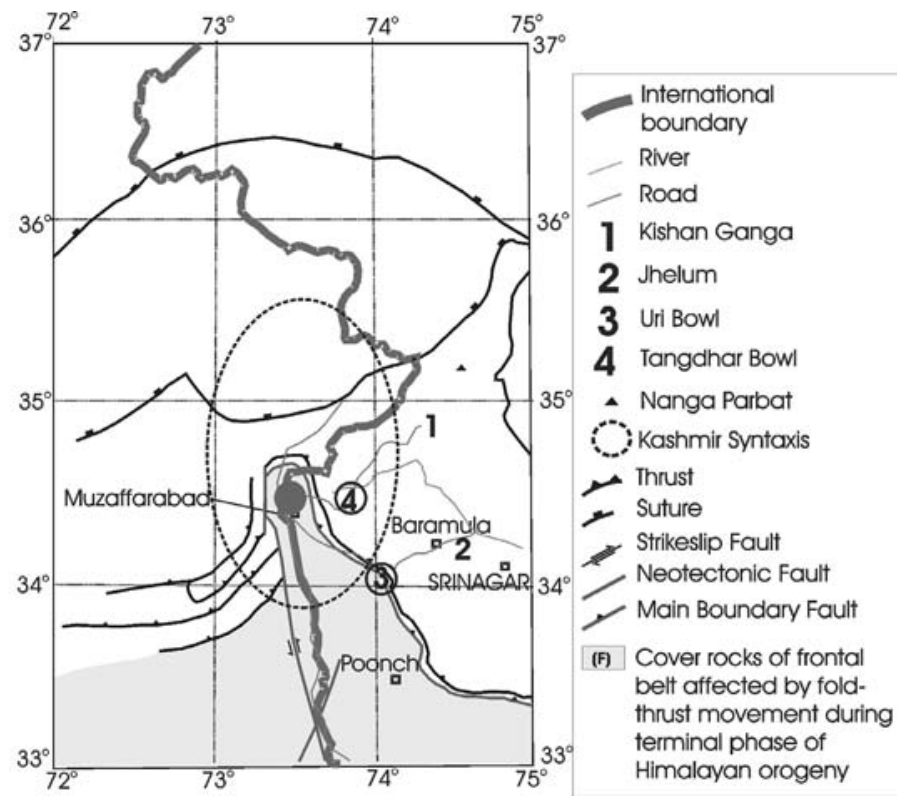

FIGURE 1. Map shows epicenter of Kashmir earthquake of 8th October 2005. Epicentral distance of nearest point of Tangdhar and Uri bowl is approximately 25 and 60 kilometers, respectively. International boundary is redrawn according to Sol sheet 43 . Tectonics is redrawn and simplified after Seismotectonic Atlas of India (GSI 2000). 